\title{
Analytical sociology and social mechanisms
}

Peter Hedström and Petri Ylikoski

\section{Book Chapter, postprint version}

N.B.: When citing this work, cite the original article.

Part of: Encyclopedia of Philosophy and the Social Sciences, Ed. Byron Kaldis, 2013, pp. 27-30. ISBN: 9781412986892

DOI: https:// doi.org/ 10.4135/9781452276052.n12

Copyright: Sage Publications

Postprint available at: Linköping University Institutional Repository (DiVA)

http:/ / urn.kb.se/ resolve?urn=urn:nbn:se:liu:diva- 142402

s Tweet 


\title{
ANALYTICAL SOCIOLOGY AND SOCIAL MECHANISMS
}

\author{
Peter Hedström and Petri Ylikoski
}

Analytical sociology is a reform movement within sociology and social theory. Its identity is not based on a common object of study, a shared historical tradition in sociological theory, or an empirical research method. Rather, it is founded on the idea that social sciences should do more than describe and classify social processes. According to analytical sociologists, the primary epistemic aim of the social sciences should be causal explanation of social phenomena. Sociological theory should aim to develop clear and precise accounts of the social mechanisms by which the intentional activities of social agents bring about social phenomena.

The historical roots of analytical sociology can be traced back to the works of late nineteenth and early twentieth century sociologists such as Max Weber and Alexis de Tocqueville, and to prominent mid-twentieth century sociologists such as the early Talcott Parsons and Robert K. Merton. Among contemporary social scientists, Jon Elster, Raymond Boudon, Thomas Schelling, and James Coleman have profoundly influenced the analytical approach. Although they are rather different types of scholars, they complement each other in important ways, and they all share a commitment to precise, abstract, and action-based explanations.

The current generation of analytical sociologists are building upon the foundations laid by these authors aiming to develop an analytical middle-range approach to sociological theory that avoids the somewhat empiricist and eclectic tendencies of Merton's original middle-range approach. Examples of the recent work in this tradition can be found in anthologies edited by Hedström and Swedberg (1998), Hedström and Bearman (2009), and in a monograph by Hedström (2005). 


\section{Social mechanisms}

The core idea of analytical sociology is that sociological theory explains by specifying causal mechanisms by which social phenomena are brought about. The specifically social causal mechanisms are called social mechanisms (Hedström and Ylikoski 2010).

Analytical sociologists are dissatisfied with the traditional covering-law account of explanation that has a large number of philosophical problems and embarrassing counter examples. It has also provided justification for the use of "black-box" explanations in the social sciences as it does not require that the mechanism linking explanans and explanandum to be specified in order for an acceptable explanation to be at hand. This omission has given leeway for sloppy scholarship. In contrast to this fundamentally empiricist account of explanation, analytical sociologists require that explanations should articulate causal mechanisms rather than simply subsume phenomena under empirical generalizations (Hedström and Ylikoski 2010).

Apart from providing explanatory understanding as to why the dependency holds, the information about the causal mechanisms also provides justification for causal claims. Distinguishing between real causal claims and spurious statistical associations is a major challenge in the social sciences. The real causal dependences are transmitted via causal processes and the search for causal mechanisms directs the attention to these processes.

The idea of causal mechanisms is related to broader ideas about the growth and organization of scientific knowledge. In mechanism-based account scientific knowledge is embedded in mechanism schemes and not in empirical generalizations as in more traditional empiricist accounts. According to this view, scientific knowledge expands by adding items to or improving 
upon items already present in the toolbox of possible causal mechanisms. Understanding accumulates as the knowledge of mechanisms gets more detailed and the number of known mechanisms increases.

The mechanism idea is important in a highly specialized and fragmented discipline like sociology. Although empirical data, research methods, and substantial theories differ from one subfield of sociology to another, the general ideas about possible causal mechanisms are something these fields could share and thereby benefit from each other's work. In this vision, sociological theory provides a set of explanatory tools that can be employed and adapted to particular situations and explanatory tasks. The mechanisms are (semi-) general in the sense that most of them are not limited to any particular application. For example, the same type of mechanism can be used for (partially) explaining residential segregation and success in cultural markets.

This mechanism-based vision of knowledge has much in common with Robert K. Merton’s idea of sociological theories of the middle range (Merton 1967). A theory of middle range is a clear, precise, and simple type of theory which can be used for partially explaining a range of different phenomena, but which makes no pretense of being able to explain all social phenomena, and which is not founded upon any form of extreme reductionism in terms of its explanans. Middle-range theories isolate a few explanatory factors which explain important but delimited aspects of the outcomes to be explained.

\section{Social explananda and individual action}

The main focus of analytical sociology is on social (as distinct from psychological) explananda 
that are not definable by reference to any single member of the collectivity. Important examples of such properties include (Hedström, 2005):

- typical actions, beliefs, or desires among the members of a collectivity;

- distributions and aggregate patterns such as spatial distributions and inequalities;

- topologies of networks that describe relationships between members of a collectivity;

- informal rules or social norms that constrain the actions of the members of a collectivity.

The key insight of analytical sociology is that explanations that directly relate macro variables to each other are unsatisfactory. They do not specify the causal mechanisms by which the changes in one macro variable brings about changes in another. Deeper explanatory understanding requires opening up the black box and finding the causal mechanisms that have generated the macro-level pattern. Rather than analyzing relationships between phenomena exclusively on the macro level, one should identify the situational mechanisms by which social structures constrain individuals' action and cultural environments shape their desires and beliefs, describe the action-formation mechanisms according to which individuals choose how to act, and specify the transformational mechanisms by which individuals, through their actions and interactions, generate various intended and unintended social outcomes. Only by understanding the whole chain of situational, action-formation and transformational mechanisms, have we made sense of the observed macro-level relationship (Coleman 1990, Hedström \& Swedberg 1998).

This argument does not imply commitment to the doctrine of methodological individualism. Most formulations of methodological individualism are much stronger than the 
mechanism-based perspective requires (Udéhn 2001). Some form of structural individualism (Coleman 1990; Hedström 2005) is sufficient for the purposes of mechanism-based explanations of social phenomena. Structural individualism is a doctrine according to which all social facts, their structure and change, are in principle explicable in terms of individuals, their properties, actions, and relations to one another. Structural individualism differs from most formulations of methodological individualism by emphasizing the explanatory importance of relations and relational structures. It does not require that all explanatory facts are facts about individual agents in the strict sense: facts about topologies of social networks, about distributions of beliefs, resources or opportunities, and about institutional or informal rules and norms can have a significant role in mechanism-based explanations.

Historically analytical sociology has some of its roots in the tradition of rational choice sociology. However, current analytical sociology does not have any special commitment to the assumptions of rational choice theory. For this reason it is a mistake to take analytical sociology as rebranded rational choice sociology. Rather than relying on some preconceived ideas about human motivation or cognitive processing, the mechanism-based perspective suggests that our account of human agency should be based on findings and theories of psychological and cognitive sciences. The explanatory agenda of mechanism-based social science has some methodological implications, however. As understanding of complex phenomena is only possible in a piece-meal way, we must abstract away from many details of human mental life. Only those aspects of cognition that are relevant for the explanatory task at hand should be included in the explanation, and the explanatory task thus determines how rich the psychological assumptions must be. 
So although the mechanism-based approach emphasizes the importance of action in the explanation of social phenomena, it does not subscribe to an axiomatic vision according to which a specific action theory should be used for all purposes. As different theories of action emphasize different aspects of human action, the choice between them should be made on methodological grounds. In some modeling contexts rational choice theory is a natural choice, while in contexts where the emphasis on the habitual dimensions of human actions, analytical sociologist might choose to employ some psychological dual-process theory. For many social scientific purposes, a relatively simple desire-belief-opportunity model will be sufficient (Hedström 2005). This simple theory provides a building block for accounts of social mechanisms of interaction through which the actions of some actors may come to influence the beliefs, desires, opportunities, and actions of others.

\section{Agent-based modeling}

A recent development in analytical sociology has been the use of agent based computer simulations (Macy and Flache 2009). Much of the development of mechanism-based knowledge consists of developing how-possibly explanation schemes. These schemes are not intended to explain any particular empirical facts directly, but to provide a general understanding of how things could work. Given the limitations of experimental methods and the complexity of social phenomena, computer simulations are important for this kind of endeavor.

The promise of agent-based simulation is based on the fact that the dynamics observed at the social level typically are complex and hard to understand, but often it is possible to describe the basic cogs and wheels of these social processes with rather simple models. Macro-level 
outcomes and relationships tell us very little about why we observe the macro-level outcomes and relationships we observe. Only by explicitly considering the micro-level actions and relations and how they unfold over time can macro-level outcomes be explained. This basic insight is at the heart of analytical sociology: To understand collective dynamics, we must study the collectivity as a whole, but we must not study it as a collective entity.

One important feature of agent-based simulations is that they do not impose any a priori constraints on the mechanisms assumed to be operating. Unlike rational choice theory, agent-based modeling is not based on any specific theory of action or interaction. It is a methodology for deriving the social outcomes that groups of interacting actors are likely to generate, whatever the action logics or interaction structures may be. Agent-based simulations should not only be regarded as a tool for theoretical exploration, however. Empirically calibrated agent-based models make it possible to integrate theoretical ideas with the results of empirical research.

\section{Conclusion}

Mechanism talk is becoming increasingly popular in the social sciences. Many sociologists use the word "mechanism" in a loose sense without any commitment to the type of mechanism-based explanatory strategy focused upon here. Underlying the mechanism-based approach is a commitment to realism: The explanations should reflect the causal processes responsible for the phenomenon to be explained. This requires stringency in theoretical practice and imagination in the design of empirical research. It also implies the social scientists should pay attention to what mechanisms are made of rather than treating them as black boxes. 


\section{References}

Coleman, J.S. (1990) Foundations of Social Theory. Cambridge, MA: The Belknap Press of the Harvard University Press.

Hedström, P. (2005) Dissecting the Social: On the Principles of Analytical Sociology. Cambridge: Cambridge University Press.

Hedström, P. and R. Swedberg (eds) (1998) Social Mechanisms: An Analytical Approach to Social Theory. Cambridge: Cambridge University Press.

Hedström, P. and P. Bearman (eds) (2009) The Oxford Handbook of Analytical Sociology. Oxford: Oxford University Press.

Hedström, P. and P. Ylikoski (2010) 'Causal Mechanisms in the Social Sciences', Annual Review of Sociology, 36: 49-67.

Macy, M.W. and A. Flache (2009) 'Population dynamics from the bottom up: Agent-based models of social interaction', in P. Hedström and P. Bearman (eds) The Oxford Handbook of Analytical Sociology. Oxford: Oxford University Press. pp. 245-268.

Merton, R.K. (1967) On Theoretical Sociology. New York: The Free Press.

Udéhn, L. (2001) Methodological Individualism: Background, History and Meaning. London: Routledge. 